\title{
Propofol-induced miR-125a-5p inhibits the proliferation and metastasis of ovarian cancer by suppressing LIN28B
}

\author{
JUAN ZENG ${ }^{1}$, YU-KUN LI ${ }^{2}$, FEI-FEI QUAN ${ }^{3,4}$, XIN ZENG $^{5}$, CHANG-YE CHEN ${ }^{4}$, \\ TIAN ZENG ${ }^{2}$, JUAN ZOU ${ }^{2}$ and WEN-JUAN TONG ${ }^{6}$
}

\author{
${ }^{1}$ Department of Anesthesiology, The Second Affiliated Hospital of University of South China; \\ ${ }^{2}$ Hunan Province Key Laboratory of Tumor Cellular \& Molecular Pathology, Cancer Research Institute, \\ University of South China, Hengyang, Hunan 421001; ${ }^{3}$ Department of Gynecology, Foshan First People's Hospital, \\ Foshan, Guangdong 528000; ${ }^{4}$ Department of Gynecology, The First Affiliated Hospital of University of South China; \\ ${ }^{5}$ Department of Histology and Embryology, Clinical Anatomy and Reproductive Medicine Application Institute, \\ University of South China; ${ }^{6}$ Department of Obstetrics, The First Affiliated Hospital of University of South China,
} Hengyang, Hunan 421001, P.R. China

Received November 23, 2019; Accepted May 1, 2020

DOI: $10.3892 / \mathrm{mmr} .2020 .11223$

\begin{abstract}
Propofol, a commonly used intravenous anesthetic agent during surgery, has relatively widespread pharmacological actions. Previous studies have reported that propofol may act as an antitumor drug in several cancer types, such as pancreatic cancer, lung cancer and gastric cancer. However, the underlying mechanism in ovarian cancer remain unknown. Therefore, the present study investigated the pharmacological effect of propofol on microRNAs (miRNAs) in ovarian cancer treatment. Propofol $(1,5$ or $10 \mu \mathrm{g} / \mathrm{ml})$ was used to treat A2780 and SKOV3 ovarian cancer cells for 1, 2, 3, 4 or 5 days. The MTT assay was used to detect cell viability, while wound healing and Transwell assays were utilized to assess the invasive and migratory abilities. The bioinformatics prediction approach identified differentially expressed miRNAs (miRs) that were used in Gene Ontology, Gene Set Enrichment Analysis and Kyoto Encyclopedia of Genes and Genomes analyses. The expression levels of miR-125a-5p and lin-28 homolog B (LIN28B) were evaluated by reverse transcription-quantitative PCR (RT-qPCR). A luciferase assay was performed to identify the relationship between miR-125a-5p and LIN28B. Western blotting was conducted to measure
\end{abstract}

Correspondence to: Dr Juan Zou, Hunan Province Key Laboratory of Tumor Cellular \& Molecular Pathology, Cancer Research Institute, University of South China, 28 West Changsheng Road, Hengyang, Hunan 421001, P.R. China

E-mail: 185443094@qq.com

Dr Wen-Juan Tong, Department of Obstetrics, The First Affiliated Hospital of University of South China, 69 Chuanshan Road, Hengyang, Hunan 421001, P.R. China

E-mail: 474294015@qq.com

Key words: ovarian cancer, propofol, bioinformatics analysis, microRNA-125a-5p, lin-28 homolog B the protein expression of LIN28B. It was demonstrated that propofol significantly upregulated miR-125a-5p to exert its antitumor activity. RT-qPCR results suggested that propofol could upregulate miR-125a-5p and LIN28B expression levels in ovarian cancer cell lines. Western blot analysis also indicated that propofol could enhance the expression of LIN28B in ovarian cancer cell lines. The luciferase assay identified that miR-125a-5p could directly inhibit the expression of LIN28B to suppress proliferation and metastasis in ovarian cancer. In conclusion, these results suggested that propofol inhibited ovarian cancer proliferation and metastasis by enhancing miR-125a-5p, which targets LIN28B.

\section{Introduction}

Ovarian cancer is the 8th leading cause of gynecological cancer type mortalities and cancer-associated incidence rates worldwide (1). The long-term survival rates of patients with ovarian cancer vary between 40-45\% depending on diverse pathological types and clinical stages (2). Difficulties in effectively treating ovarian cancer with regards to its formation, development and progression remain challenging due to the multivariate risk factors of this disease, the diagnosis at a terminal stage and poor prognosis (3). Moreover, advances in treatment strategies, including hormonotherapy, immunotherapy, surgical operation, chemotherapy and radiological intervention, have not increased the long-term survival rate of patients with ovarian cancer (4). Therefore, effective anticancer therapies with few side effects are urgently required.

Propofol, a short-acting intravenous sedative hypnotic reagent used during and after operation, is one of the most widely accepted and commonly used intravenous sedative hypnotic agents and has multiple advantages over other types of these reagents in protecting neurocytes from oxidative stress and hypoxia injury (5), as well as exerting several non-anesthetic effects (6). Previous studies have reported that suppressive effects of propofol are observed in different 
cancer types. For example, it has been revealed that propofol suppressed the proliferative ability and epithelial-mesenchymal transition cascades by enhancing the expression of microRNA (miRNA/miR)-1284 in A549 lung cancer cells (7). In endometrial cancer, Du et al (8) reported that propofol decreased cellular proliferation, migration and invasion, but induced apoptosis of endometrial cancer cells by regulating Sox4.

Previous studies investigating the tumor-suppressing effects of miR-125a-5p have shown that downregulated miR-125a-5p is found in multiple types of cancer $(9,10)$. Zhang et al (11) revealed that lin-28 homologue B (LIN28B) was a direct target of miR-125a-5p in melanoma. Furthermore, Yong et al (12) demonstrated that LIN28B expression was increased in ovarian cancer, which could promote the cellular proliferation and migration. LIN28B has a close association with proliferation, apoptosis, metastasis, growth and oncogenesis in colon cancer, non-small cell lung cancer, esophageal cancer, prostate cancer, peripheral T-cell lymphoma, breast cancer, nasopharyngeal carcinoma, renal cell cancer, hepatocellular carcinoma and ovarian cancer (13-15). Therefore, it was hypothesized that propofol could inhibit the expression of LIN28B to reduce proliferation and metastasis by regulating miR-125a-5p in ovarian cancer. The present study may offer a novel and important insight into the use of anesthetics in the surgical operation of ovarian cancer treatment.

\section{Materials and methods}

Bioinformatic analysis. Bioinformatic analysis was performed on the GSE119055 dataset (https://www.ncbi.nlm. nih.gov/gds/?term=) that was submitted by Dong et al (16) which contained six ovarian cancer tissues and three healthy ovarian tissues, and was based on the GPL21572 (miRNA-4) Affymetrix Multispecies miRNA-4 Array (ProbeSet ID version). Subsequently, the raw data were analyzed using several packages (pheatmap and ggplot2) of R statistical software (version 3.3.2; https://www.r-project.org/) (17) to obtain a heat map, volcano plots. Visualization of Gene Ontology (GO; http:/geneontology.org/) Slim summary, Gene Set Enrichment Analysis (GSEA), and Kyoto Encyclopedia of Genes and Genomes analyses (KEGG) pathway enrichment (https://www. kegg.jp/) were performed (http://www.linkedomics.org/login. php), which are efficient methods to visualize large amounts of genomic information (18). TargetScan (http://www. targetscan.org) (19), miRTarBase (http://mirtarbase.mbc.nctu. edu. tw/php/index.php) (20), and miRDB (http://www.mirdb. $\mathrm{org} /$ ) (21) were used to predict potential targets of miR-125a-5p.

Cell culture. Human ovarian cancer cell lines, A2780 and SKOV3 (American Type Culture Collection), were cultured in RPMI-1640 medium(Sigma-Aldrich; Thermo Fisher Scientific, Inc.) supplemented with $1 \%(\mathrm{v} / \mathrm{v})$ Penicillin-Streptomycin mixture (Thermo Fisher Scientific, Inc.) and 10\% (v/v) fetal bovine serum (FBS; Gibco; Invitrogen; Thermo Fisher Scientific, Inc.). Cells were treated with propofol (Sigma-Aldrich; Merck KGaA; $1-10 \mu \mathrm{g} / \mathrm{ml}$ ) for $48 \mathrm{~h}$ at $37^{\circ} \mathrm{C}$, or were cultured at different time points $(0,12,24,48 \mathrm{~h})$ at $10 \mu \mathrm{g} / \mathrm{ml}$. All cells were cultured in a humidified atmosphere of $5 \% \mathrm{CO}_{2}$ and $95 \%$ air at $37^{\circ} \mathrm{C}$.
Cell viability assays. For MTT assay, cells were seeded in 96-well $\left(1 \times 10^{3}\right.$ cells/well) and treated with $0,1,5,10 \mu \mathrm{g} / \mathrm{ml}$ of propofol for $48 \mathrm{~h}$ at $37^{\circ} \mathrm{C}$. A total of $5 \times 10^{3}$ cells/well were seeded into 96 -well plates and cultured for 1, 2, 3, 4 and 5 days at $37^{\circ} \mathrm{C}$. Twenty microliters MTT solution $(5 \mathrm{mg} / \mathrm{ml}$, Sigma-Aldrich; Merck KGaA) was incubated for $4 \mathrm{~h}$ at $37^{\circ} \mathrm{C}$. Then, $150 \mu 1$ DMSO was added to dissolve the precipitates and the effect of cell number on absorbance at $490 \mathrm{~nm}$ was measured using a microplate reader (Molecular Devices, LLC). The experiments were performed in triplicate.

Wound healing assay. For wound healing assay, A2780 and SKOV3 cells were plated in a 6 -well plate $\left(5 \times 10^{5}\right.$ cells/well $)$ and were cultured to confluence as a monolayer at $5 \% \mathrm{CO}_{2}$ and $95 \%$ air at $37^{\circ} \mathrm{C}$. The monolayer was scratched with a $10 \mu \mathrm{l}$ plastic pipette tip and washed twice with PBS to remove injured cells, which were cultured with DMEM without serum and treated with $0,1,5,10 \mu \mathrm{g} / \mathrm{ml}$ of propofol for $48 \mathrm{~h}$ at $37^{\circ} \mathrm{C}$. The images of the wounded cell monolayer were captured and evaluated using a light microscope (magnification, $x 40$; Nikon Corporation). Then, the data of wound healing area were analyzed by image analysis software (ImageJ v1.8.0, National Institutes of Health).

Transwell migration and invasion assays. For cell transfection, LIN28B-shRNA (no. 1, no. 2; Sigma-Aldrich; Merck KGaA) and scramble-shRNA plasmids (no 1; Sigma-Aldrich; Merck KGaA) were transfected into A2780 cells. Cells were transfected with $2 \mu \mathrm{g}$ of each plasmid in six-well plates with Lipofectamine ${ }^{\circledR} 2000$ (Thermo Fisher Scientific, Inc.). Following cell culture in the medium with $2 \mu \mathrm{g} / \mathrm{ml}$ puromycin for $72 \mathrm{~h}$, cell monoclonal culture from single cell was performed. After 12 days of cell culture, the knockdown efficiency was examined by Western blot analysis. Scramble-shRNA transfected cells were used as the negative control for LIN28B-knockdown cells. A Transwell assay was utilized to demonstrate the migratory and invasive abilities of A2780 and SKOV3 cells after transfection with LIN28B short hairpin (sh)RNA or co-incubation with propofol in $0,1,5$ and $10 \mu \mathrm{g} / \mathrm{ml}$ at $37^{\circ} \mathrm{C}$ for $72 \mathrm{~h}$. Cells were added to the Transwell chamber ( $8 \mu \mathrm{m}$ pore size; BD Biosciences). The number of cells that migrated through the membrane was determined $8 \mathrm{~h}$ later. For invasion assay, Matrigel (BD Biosciences) was mixed with 1640 medium at a ratio of 1:6 and was placed into upper chambers at $37^{\circ} \mathrm{C}$ for $30 \mathrm{~min}$ in a $5 \% \mathrm{CO}_{2}$ incubator overnight prior to addition of cells. For migration assay, Matrigel was not used. Then, $150 \mu \mathrm{l}$ cell suspension $\left(2.5 \times 10^{4}\right.$ cells $)$ was plated to the upper chamber with serum-free medium and cell medium with $10 \%$ FBS was placed into lower chambers, which was incubated at $37^{\circ} \mathrm{C}$ for $24 \mathrm{~h}$. Migrated and invaded cells were determined by crystal violet staining at $37^{\circ} \mathrm{C}$ for $15 \mathrm{~min}$ and were subsequently counted by an inverted light microscope (magnification, $\mathrm{x} 40$; Nikon Corporation) using ImageJ v1.8.0 (National Institutes of Health).

Reverse transcription-quantitative PCR (RT-qPCR). A2780 cells were treated with $0,1,5$ and $10 \mu \mathrm{g} / \mathrm{ml}$ of propofol for $48 \mathrm{~h}$ at $37^{\circ} \mathrm{C}$ and A2780 cells administered $10 \mu \mathrm{g} / \mathrm{ml}$ propofol for 0 , 12,24 and $48 \mathrm{~h}$ were analyzed by RT-qPCR. Total cellular RNA was extracted with TRIzol ${ }^{\circledR}$ (Invitrogen; Thermo Fisher Scientific, Inc.) following the manufacturer's instructions. Then, 
1,000 ng total RNA was reverse transcribed using TaqMan miRNA RT kit (Applied Biosystems; Thermo Fisher Scientific, Inc.) for $1 \mathrm{~h}$ at $37^{\circ} \mathrm{C}$. qPCR (SYBR ${ }^{\circledR}$ Premix Ex Taq II; Takara Biotechnology Co., Ltd.) was performed on ABI 7500 Sequence Detection system (Thermo Fisher Scientific, Inc.). The thermocycling conditions were as follows: $2 \mathrm{~min}$ at $50^{\circ} \mathrm{C}$ and $10 \mathrm{~min}$ at $95^{\circ} \mathrm{C}$ followed by 40 cycles of $95^{\circ} \mathrm{C}$ for $3 \mathrm{sec}$ and $60^{\circ} \mathrm{C}$ for $30 \mathrm{sec}$. The expression level of miRNA was normalized by U6. The expression level of RNA was normalized to $\beta$-actin. The following primers were used: $\beta$-actin forward, 5 -ACCCTGAAG TACCCCATCGAG-3' and reverse, 5'-AGCACAGCCTGGA TAGCAAC-3'; U6 forward, 5'-CTCGCTTCGGCAGCACA TATACT-3' and reverse, 5'-ACGCTTCACGAATTTGCGT GTC-3'; miR-125a-5p forward, 5'-CGATTCCCTGAGACCCTT TAA-3' and reverse, 5'-TATGGTTTTGACGACTGTGTGAT-3'; and LIN28B forward, 5'-GTCAATACGGGTAACAGGAC-3' and reverse, 5'-TTCTTTGGCTGAGGAGGTAG-3' The expression level of miR-125a-5p was calculated using the $2^{-\Delta \Delta \mathrm{Cq}}$ method (22), whereby $\Delta \mathrm{Cq}=\mathrm{Cq}$ (miR-125a-5p)-Cq (U6). The expression level of LIN28B was calculated using the $2^{-\Delta \Delta C q}$ method, whereby $\Delta \mathrm{Cq}=\mathrm{Cq}(\mathrm{LIN} 28 \mathrm{~B})-\mathrm{Cq}(\beta$-actin).

Luciferase reporter assays. Luciferase assays were used in A2780 cells. Wild-type 3'-UTR of LIN28B and mutant controls were constructed and inserted into the psiCheck2 Luciferase vector (Promega Corporation). The psi-CHECK2 vector (cat. no. C8021) was purchased from Promega Corporation. The miR-125a-5p mimics and negative control (NC) mimics, and miR-125a-5p inhibitor and NC inhibitor were synthesized by Guangzhou RiboBio Co., Ltd., and transfected into 24-well plate at $50 \mathrm{nM}$ using Lipofectamine ${ }^{\circledR} 2000$ (Invitrogen; Thermo Fisher Scientific, Inc.), according to the manufacturer's instructions. Next, cells were harvested. Firefly and Renilla luciferase activities were measured with the dual-luciferase assay kit (Promega Corporation) at $48 \mathrm{~h}$ after transfection. Then, cells were collected and lysed. The luciferase activity was subsequently measured using a Dual Luciferase Reporter Assay System Kit (Promega Corporation) on a Luminometer TD-20/20 detector (E5311; Promega Corporation), and the relative luciferase activity was expressed by Firefly/Renilla luciferase activity. The mimics sequence (5'-UCCCUGAGACCCUUU AACCUGUGA-3'), inhibitors sequence (5'-TCACAGGUU AAAGGGTCTCAGGGA-3'), mimic NC sequence (5'-GGACC AAATCTCGAGATTTGG-3') and inhibitor NC sequence (5'-UUCUCCGAACGUGUCACGUU-3') were all designed as chemically modified double strands.

Western blot analysis. Cells were homogenized and sonicated in RIPA buffer (Sigma-Aldrich; Merck KGaA) on ice. Western blotting was conducted according to our previous report (23). Determination of protein content: A small amount of the supernatant was taken with a pipette, and the absorbance was measured by a visible spectrophotometer at a wavelength of $590 \mathrm{~nm}$ according to the Bradford method. Using solvent as the blank control and Bovine Serum Albumin (BSA) as the standard control a curve was drawn, and the content of the protein in the extracted sample was estimated based on the standard curve. The extracted protein was collected, denatured and electrophoresed through a $10 \%$ SDS-polyacrylamide gel. Samples were loaded and electrophoresis was performed for 60-90 min followed by transfer to PVDF membranes and blocking in $5 \%$ skimmed milk at $37^{\circ} \mathrm{C}$. After shaking for $2 \mathrm{~h}$, elution was performed. Following this, membranes were incubated with the primary antibodies (LIN28B; Abcam, cat. no. ab229628, 1:1,000 dilution) at $4^{\circ} \mathrm{C}$ overnight with shaking. Membranes were then incubated in secondary antibodies (conjugated goat anti rabbit IgG; CWBIO, cat. no. CW0103S, 1:2,000 dilution,) at room temperature for $2 \mathrm{~h}$ and washed in TBST three times for $15 \mathrm{~min}$. The Western blot analysis was detected by a chemiluminescent method. The membranes were then incubated in Super Signal ECL-HRP detection reagent (ComWin Biotech) for $1 \mathrm{~min}$ followed by exposure to film in a visualizer.

Statistical analysis. Data are presented as the mean \pm SD. All assays were tested in three independent experiments. Experimental data were analyzed using SPSS statistical software (version 12.0; SPSS Inc.). The significance of the group difference was evaluated by one-way analysis of variance followed by Tukey's post hoc test. Multiple comparisons between the groups were performed using Student-Newman-Keuls method. $\mathrm{P}<0.05$ was considered to indicate a statistically significant difference.

\section{Results}

Propofol suppresses the proliferation of ovarian cancer cells. To assess whether the effects of 1,5 and $10 \mu \mathrm{g} / \mathrm{ml}$ propofol suppress cell viability, the cytotoxicity of propofol was tested in A2780 and SKOV3 cells. It was demonstrated that propofol decreased A2780 and SKOV3 cell viability in a dose-dependent manner (Fig. 1A and B). It was found that $10 \mu \mathrm{g} / \mathrm{ml}$ propofol had the strongest inhibitory effect on A2780 and SKOV3 cells. Furthermore, the MTT assay results indicated that propofol treatment $(10 \mu \mathrm{g} / \mathrm{ml})$ significantly inhibited the proliferation of A2780 and SKOV3 cells (Fig. 1C and D).

Migration and invasion of ovarian cancer cells are attenuated by propofol. Subsequently, the effects of propofol on A2780 and SKOV3 cell migratory and invasive abilities were examined. The wound healing assay results suggested that treatment with $10 \mu \mathrm{g} / \mathrm{ml}$ propofol markedly inhibited the migration of A2780 and SKOV3 cells compared to NC group (Fig. 2A). To further demonstrate the suppressive effects of propofol on cell migration and invasion, Transwell assays were performed. These findings also indicated that propofol notably suppressed the migration and invasion of ovarian cancer cells (Fig. 2B).

Bioinformatics analysis of women with ovarian cancer. miRNA expression profiles were downloaded from the Gene Expression Omnibus database (ID, GSE119055) to analyze differentially expressed miRNAs. This analysis identified 45 microRNAs with differential expression in ovarian cancer compared with healthy ovarian tissue (Fig. 3A and B). Among these, the expression of miR-125a-5p was lower in patients with ovarian cancer compared with healthy ovarian tissue (Fig. 3C). Within the top 30 candidate miRNAs analyzed, it was found that the expression of miR-125a-5p was lower in cancer tissues compared with healthy tissues (Fig. 3A). Collectively, these results indicated that miR-125a-5p expression was lower in ovarian cancer, resulting in a poor prognosis. 
A

A2780

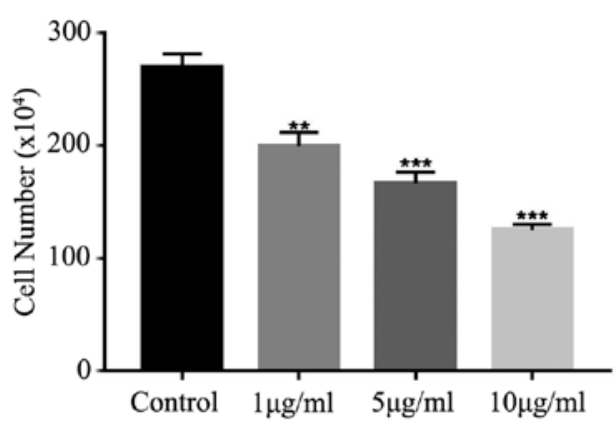

C

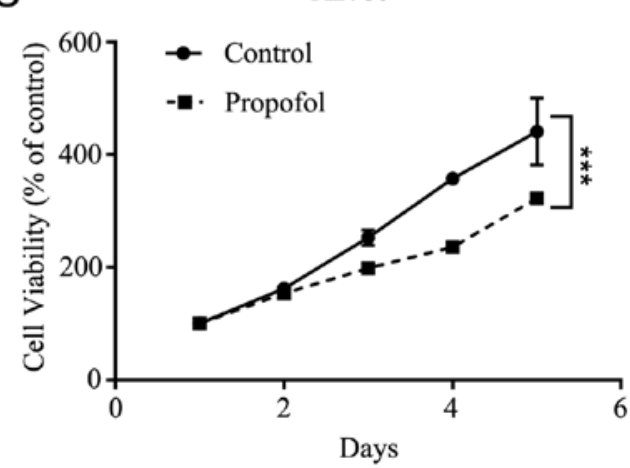

B

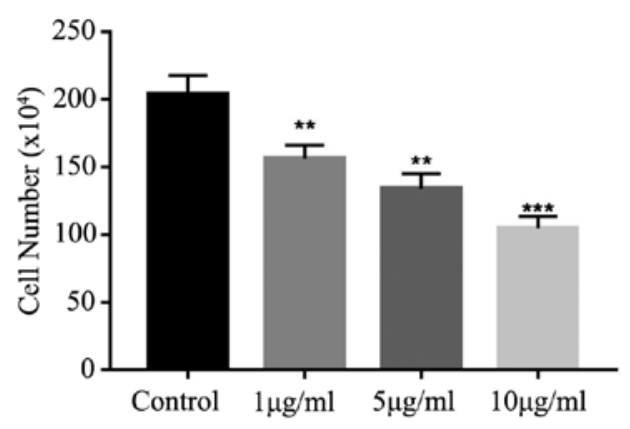

D

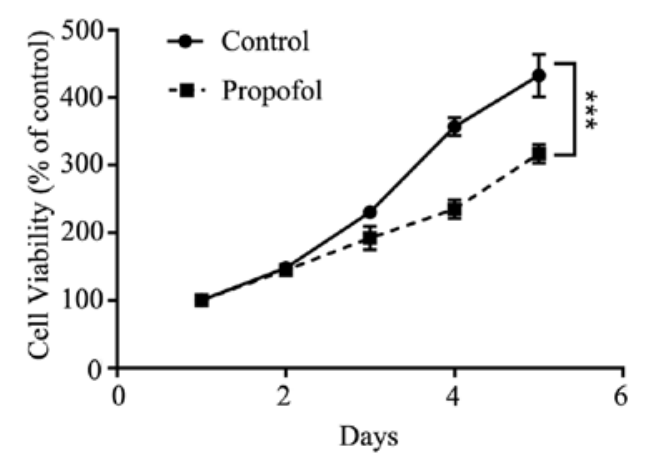

Figure 1. Proliferation of ovarian cancer is inhibited by propofol. (A) Proliferation of (A) A2780 cells and (B) SKOV3 cells was measured by cell counts assay under different concentration of propofol. Viability of (C) A2780 cells and (D) SKOV3 cells was evaluated by MTT assay in $10 \mu \mathrm{g} / \mathrm{ml}$ propofol. Data are presented as the mean $\pm \mathrm{SD} .{ }^{* *} \mathrm{P}<0.01,{ }^{* * *} \mathrm{P}<0.001$ vs. control.

GO analysis and GSEA of co-expressed genes correlated with miR-125a-5p in ovarian cancer. The present study analyzed mRNA sequencing data from 453 patients with ovarian cancer in The Cancer Genome Atlas (TCGA). As shown in the heat map and volcano plot (Fig. 4A and B), 3,395 genes (dark red dots) were significantly upregulated along with miR-125a-5p, while 3,031 genes (dark green dots) were significantly downregulated (false discovery rate $<0.01$ ). In total, 50 hub genes were positively and negatively associated with miR-125a-5p, as presented in the heat map (Fig. 4A). These results indicated a significant and wide pathophysiological effect of miR-125a-5p on gene transcription. The list of co-expressed genes associated with miR-125a-5p contained 6,426 gene IDs of which 5,188 gene IDs were unambiguously mapped to 5,188 unique Entrez gene IDs and 1,238 user IDs could not be mapped to any Entrez gene ID.

The GO Slim summary indicated a notable quantity variance and significance level difference among the 5,188 differentially expressed genes (DEGs) that were enriched in biological processes, molecular functions and cellular components. For biological processes, these 5,188 genes regulated by miR-125a-5p were mainly enriched in 'biological regulation', including 'cell proliferation', 'growth', 'metabolic process' and 'cell communication', thus suggesting that miR-125a-5p could act as an anticarcinogen to inhibit ovarian cancer by mediating biological regulation. For cellular components, the genes were largely enriched in the 'membrane', including 'cell projection', 'cytoskeleton' and 'extracellular matrix', indicating that miR-125a-5p could regulate membrane components to control cell movement and organization. For molecular functions, the genes were mainly enriched in 'protein binding' and 'enzyme activity', demonstrating that miR-125a-5p could act as a regulator to mediate ovarian cancer progression (Fig. 4D).

GSEA of the 5,188 DEGs at the whole gene expression level was performed, and was used to assess the cell migration and invasion effects of DEGs that played roles in the whole gene expression level. The results demonstrated that the 5,188 DEGs regulated by miR-125a-5p were largely enriched in pathways including 'cell-cell junction', 'negative regulation of cellular component movement', 'protein complex involved in cell adhesion' and 'cell-cell adhesion via plasma-membrane adhesion molecules', which indicated that miR-125a-5p could mediate cell migration and invasion in ovarian cancer (Fig. 4C).

Expression of miR-125a-5p is enhanced by propofol in ovarian cancer cells. It has been revealed that propofol can upregulate the expression levels of miR-199a (24) and miR-143 (25), suggesting that propofol may regulate a number of miRNAs. Therefore, the present study detected the effects of propofol on miR-125a-5p involved in ovarian cancer cells. The expression of miR-125a-5p was measured under different concentrations of propofol $(1,5$ and $10 \mu \mathrm{g} / \mathrm{ml})$, and it was found that the expression of miR-125a-5p was enhanced in a dose- and time-dependent manner (Fig. 5A and B). Furthermore, the positive effect of propofol on miR-125a-5p transcriptional activity was further tested using a luciferase assay and it was found that propofol could significantly increase the transcriptional activity of miR-125a-5p compared to NC group (Fig. 5C).

miR-125a-5p targets LIN28B to downregulate ovarian cancer cell proliferation. TargetScan (http://www. 
A

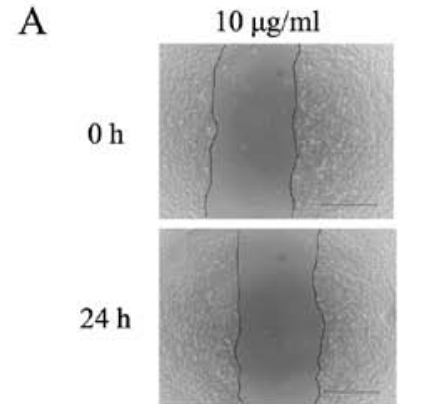

$48 \mathrm{~h}$

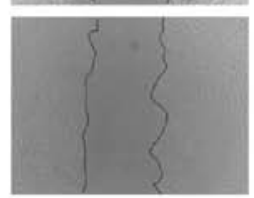

$0 \mathrm{~h}$

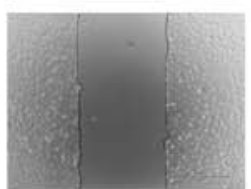

$24 \mathrm{~h}$

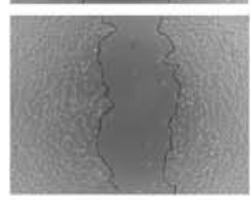

$48 \mathrm{~h}$

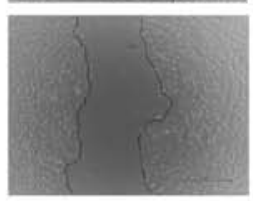

B
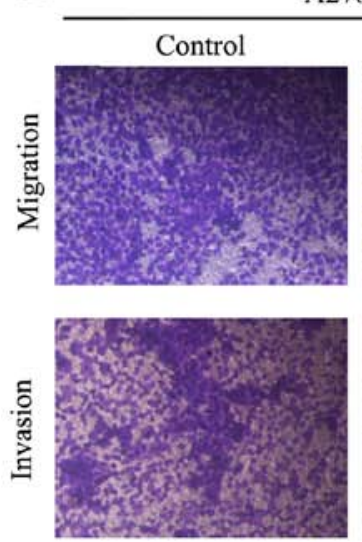

$5 \mu \mathrm{g} / \mathrm{ml}$
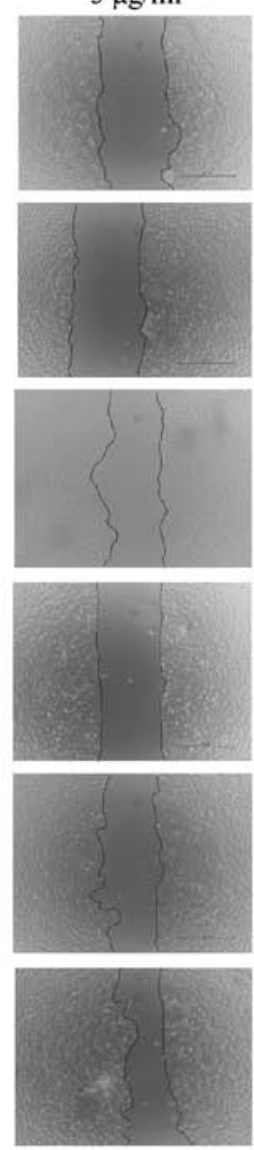

2780
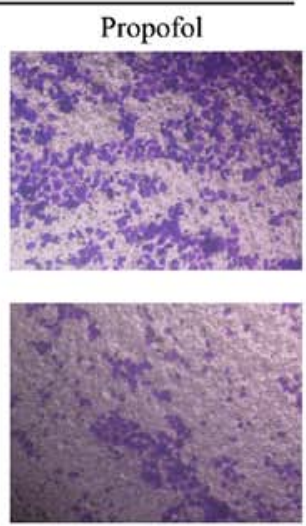

$1 \mu \mathrm{g} / \mathrm{ml}$
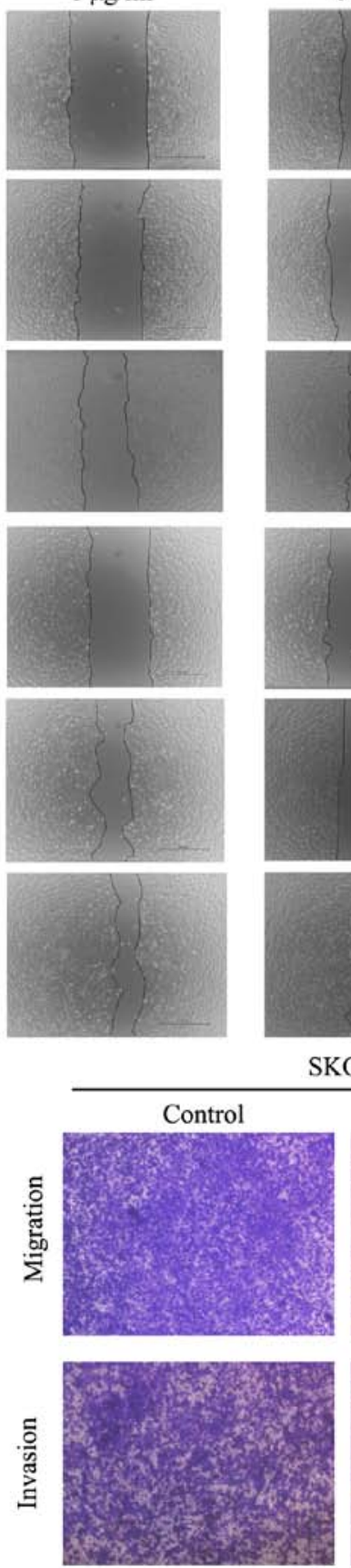

$0 \mu \mathrm{g} / \mathrm{ml}$

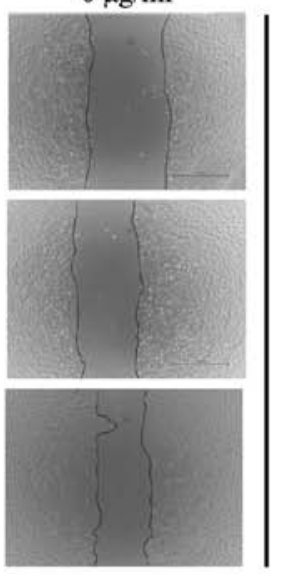

A2780

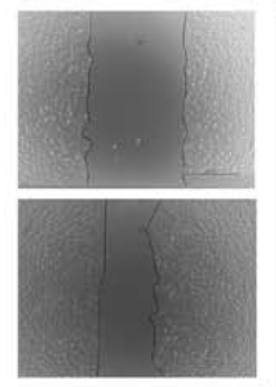

SKOV3

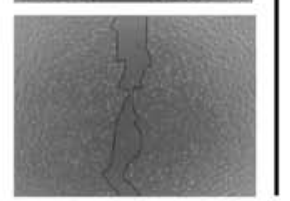

SKOV3
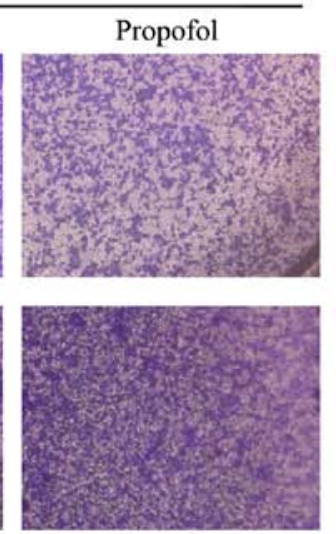

Figure 2. Propofol inhibits migration and invasion of ovarian cancer. (A) Wound healing assay of A2780 cells and SKOV3 cells administered $10 \mu \mathrm{g} / \mathrm{ml}$ propofol. Original magnification, x40. (B) Transwell migration and invasion assay of A2780 cells and SKOV3 cells administered $10 \mu \mathrm{g} / \mathrm{ml}$ propofol. Scale bar, $100 \mu \mathrm{m}$ for B. Data are presented as the mean $\pm \mathrm{SD}$.

targetscan.org), miRTarBase (http://mirtarbase.mbc.nctu. edu. tw/php/index.php), miRDB (http://www.mirdb.org/) and TCGA (https://cancergenome.nih.gov/) were used to predict potential targets of miR-125a-5p (Fig. 6A). A variety of cell proliferation-, migration- and invasion-related genes were predicted, and the level of Lin28B in these genes was subsequently assessed by RT-qPCR. It was demonstrated that LIN28B mRNA expression was significantly inhibited by miR-125a-5p mimics in A2780 and SKOV3 cells (Fig. 6B). In both ovarian cancer cell lines, miR-125a-5p mimics also significantly decreased the protein expression of LIN28B compared with the controls (Fig. 6C).
To identify the direct action of miR-125a-5p on LIN28B a luciferase assay was performed. miR-125a-5p significantly suppressed the expression of LIN28B, while LIN28B with mutant binding sites was not regulated by miR-125a-5p mimics (Fig. 6D). Furthermore, A2780 cells were transfected with miR-125a-5p inhibitor and mimics, which significantly affected the expression of miR-125a-5p (Fig. 6E and F). Cellular proliferation and viability were also inhibited by the miR-125a-5p mimic group compared with the NC group (Fig. 6G and $\mathrm{H}$ ). It was found that inhibition of miR-125a-5p could significantly enhance cell proliferation and viability compared with the control group (Fig. 6I and J). 

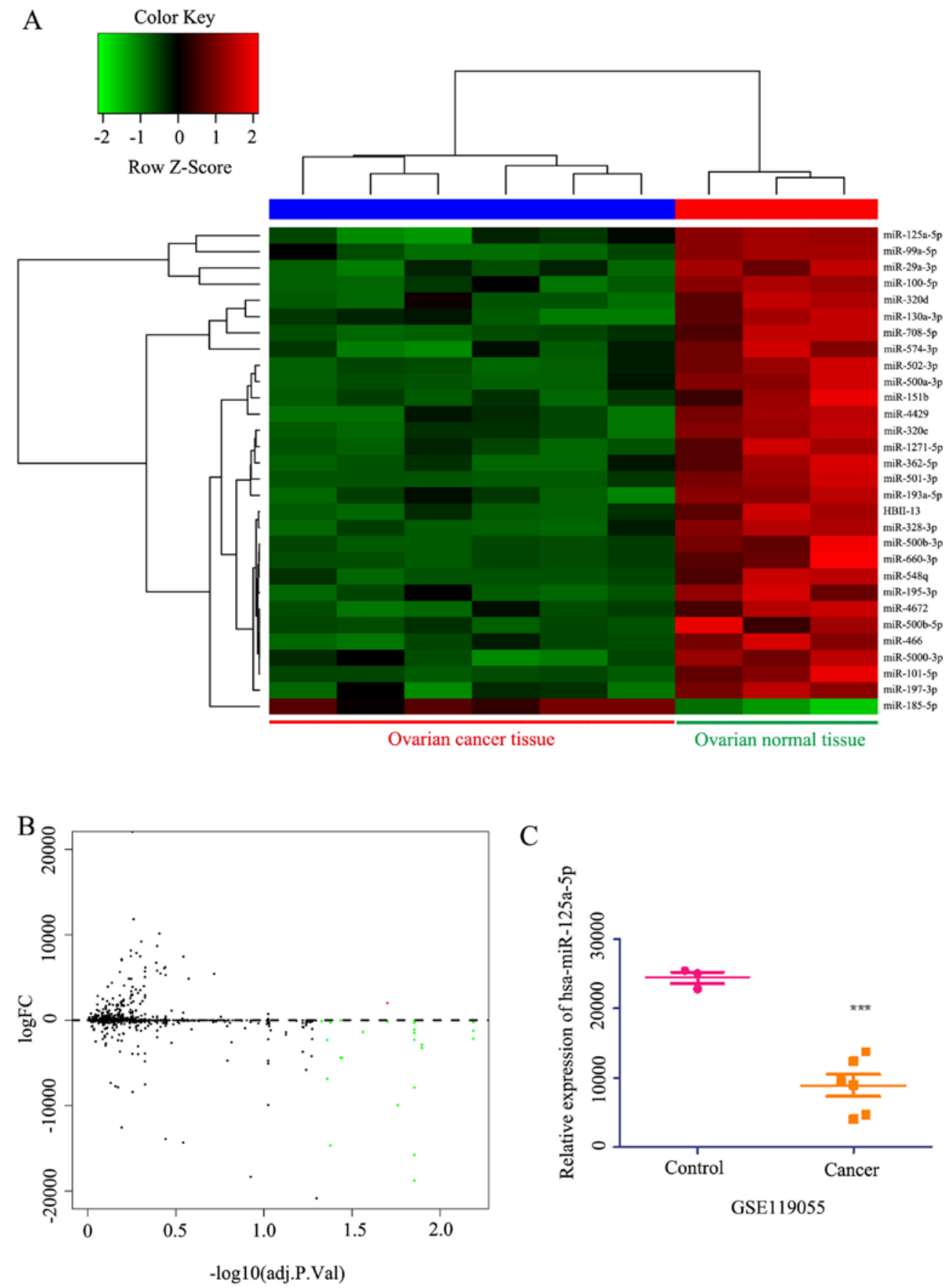

$\mathrm{C}$

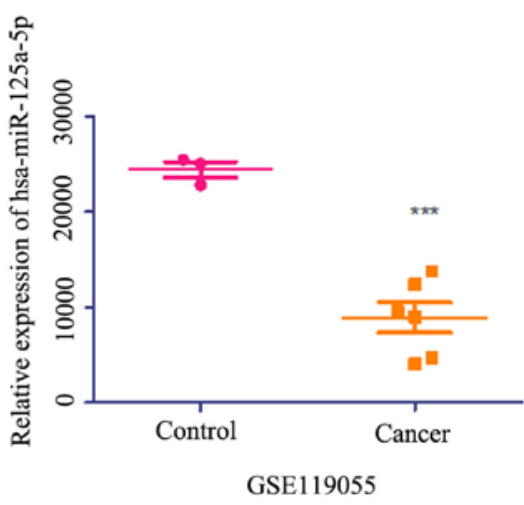

Figure 3. Heat map, Volcano plot and differential expression of miRNAs in ovarian cancer. (A) Heat map of the differentially expressed miRNAs between ovarian cancer and healthy ovarian tissue. (B) Volcano plot of the differential expressed miRNAs from GSE119055 datasets, the red dots and green dots represent the upregulated and downregulated genes, respectively ( $\log \mathrm{FC}>2$ or $<-2$ ). (C) Different expression of miR-125a-5p from GSE119055 datasets. Data are presented as the mean $\pm \mathrm{SD} .{ }^{* * *} \mathrm{P}<0.001$ vs. control. miR/miRNA, microRNA.

Expression of LIN28B is decreased by propofol in ovarian cancer cells. To determine whether the expression of LIN28B could be affected by propofol, the expression of LIN28B was measured under different concentrations of propofol $(1,5$ and $10 \mu \mathrm{g} / \mathrm{ml})$. The results indicated that the expression of LIN28B was inhibited in a dose- and time-dependent manner (Fig. 7A and C). Mechanistically, it was identified that LIN28B knockdown (KD; Fig. 7B) inhibited cellular migration and invasion (Fig. 7D). Furthermore, cell viability and numbers could be suppressed by LIN28B KD compared with the control cell line (Fig. 7E and F).

\section{Discussion}

The present study evaluated the effects of propofol on ovarian cancer A2780 and SKOV3 cells. It was found that exposure to propofol markedly inhibited proliferation, migration and invasion in ovarian cancer cells. The underlying mechanisms were investigated, and several miRNAs related to cell migration and invasion were detected. After propofol treatment, the expression of miR-125a-5p was significantly increased in a dose- and time-dependent manner in A2780 and SKOV3 cells. Previous studies have reported that propofol can upregulate the expression 


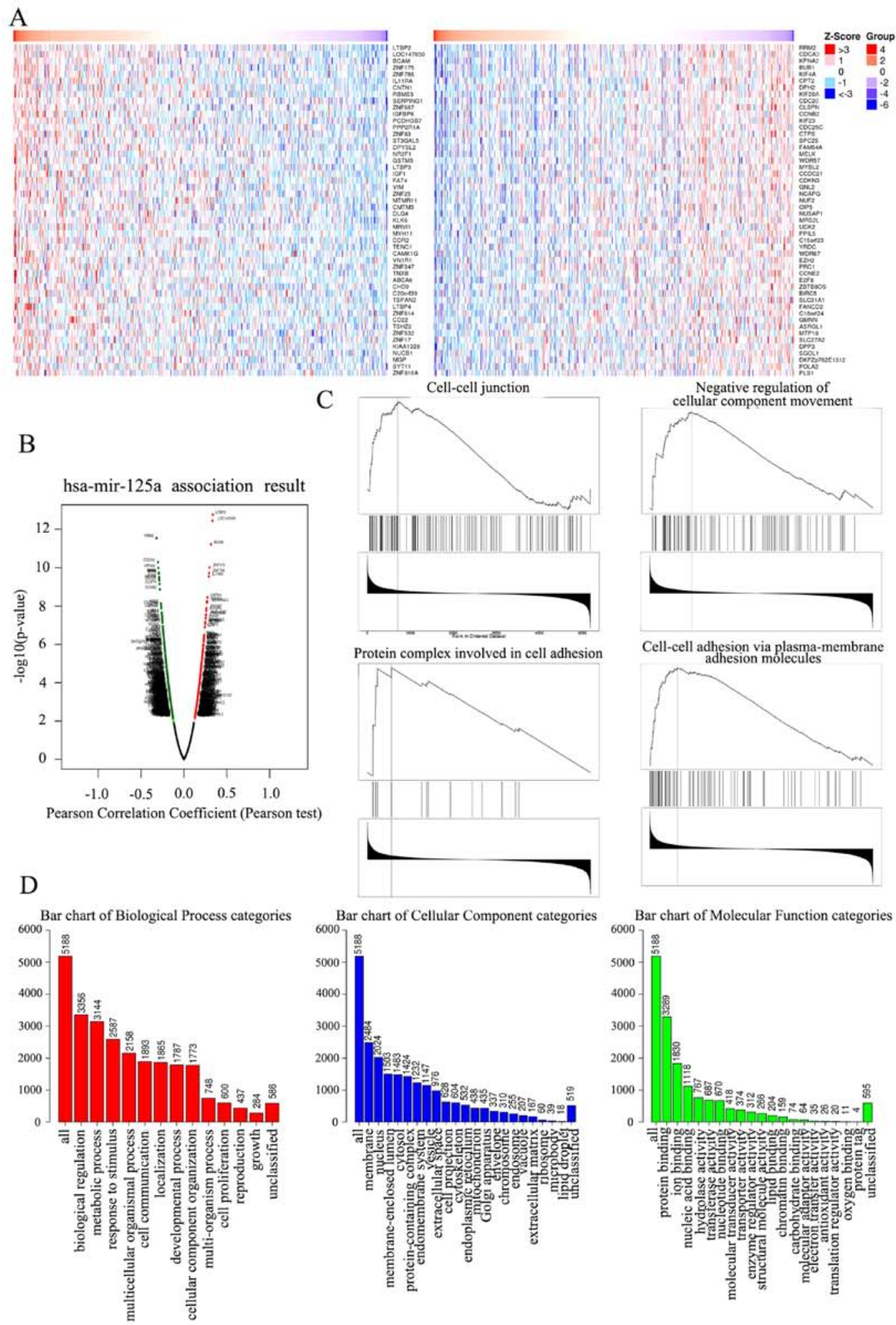

Figure 4. Heat map, Volcano plot, GSEA and GO enrichment assay in ovarian of key genes targeted by miR-125a-5p. (A) Heat map of the positive DEGs (left) and negative DEGs (right) targeted by miR-125a-5p in TCGA database. (B) Volcano plot of the DEGs targeted by miR-125a-5p in TCGA database, the red dots and green dots represent the upregulated and downregulated, respectively. (C) The four enrichment plots from the GSEA results, including 'cell-cell junction', 'negative regulation of cellular component movement', 'protein complex involved in cell adhesion' and 'cell-cell adhesion via plasma-membrane adhesion molecules'. (D) GO analysis results of DEGs. GO, Gene Ontology; miR, microRNA; DEGs, differentially expressed genes; GSEA, Gene Set Enrichment Analysis; TCGA, The Cancer Genome Atlas.

levels of miR-199a (24) and miR-143 (25), indicating that propofol can regulate miRNAs involved in cell migration and invasion. The present results also identified that LIN28B was a target of miR-125a-5p. Thus, it was speculated that propofol serves crucial roles in the inhibition of ovarian cancer cell proliferation, migration and invasion by enhancing miR-125a-5p, which targets LIN28B. Moreover, KD of LIN28B markedly enhanced cellular migration and invasion compared with the control cell line. 

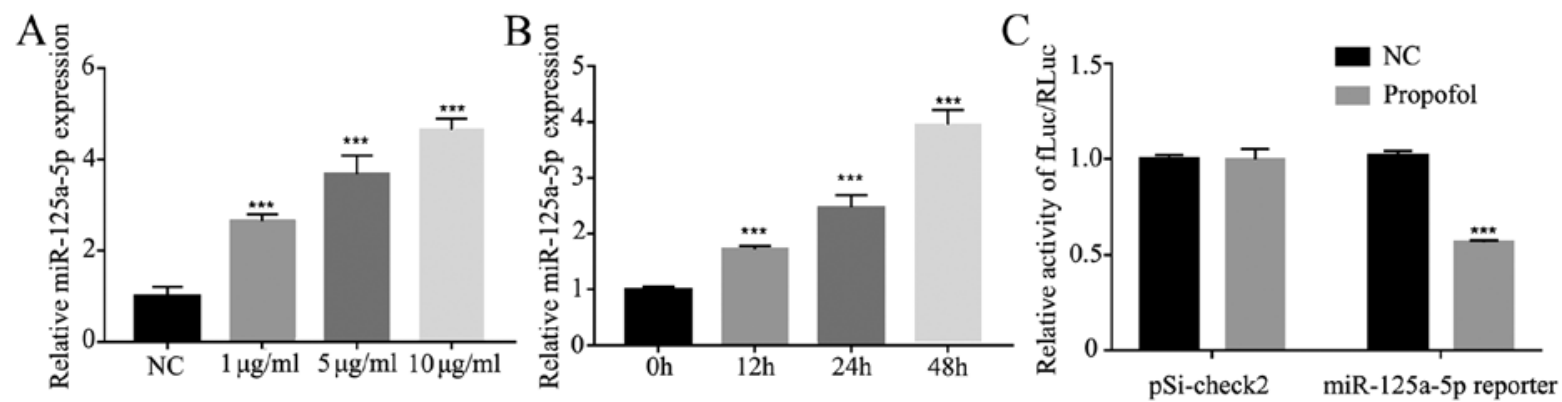

Figure 5. miR-125a-5p expression is upregulated by propofol. (A) miR-125a-5p expression in A2780 cells administered different concentration of propofol was tested by RT-qPCR. (B) miR-125a-5p expression in A2780 cells administered $10 \mu \mathrm{g} / \mathrm{ml}$ propofol for different time points was measured by RT-qPCR. (C) Luciferase reporter assay of A2780 cells transfected with miR-125a-5p reporter and treated with $10 \mu \mathrm{g} / \mathrm{ml}$ propofol. Data are presented as the mean \pm SD ${ }^{* * *} \mathrm{P}<0.001$ vs. control. NC, negative control; mir, microRNA; RT-qPCR, reverse transcription-quantitative PCR; fLuc, firefly luciferase; RLuc, Renilla luciferase.

A

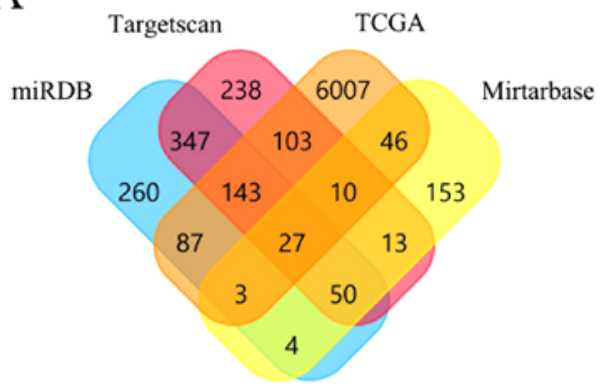

$\mathrm{C}$

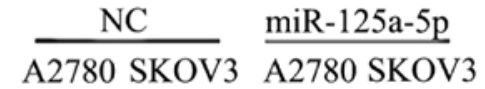

LIN28B

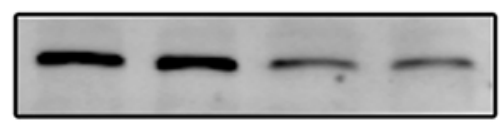

GAPDH

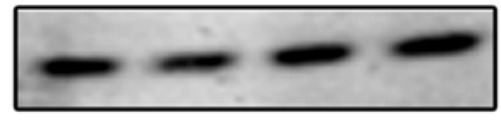

B

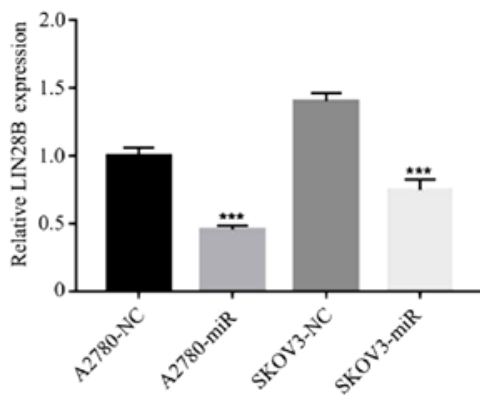

$\mathrm{D}$
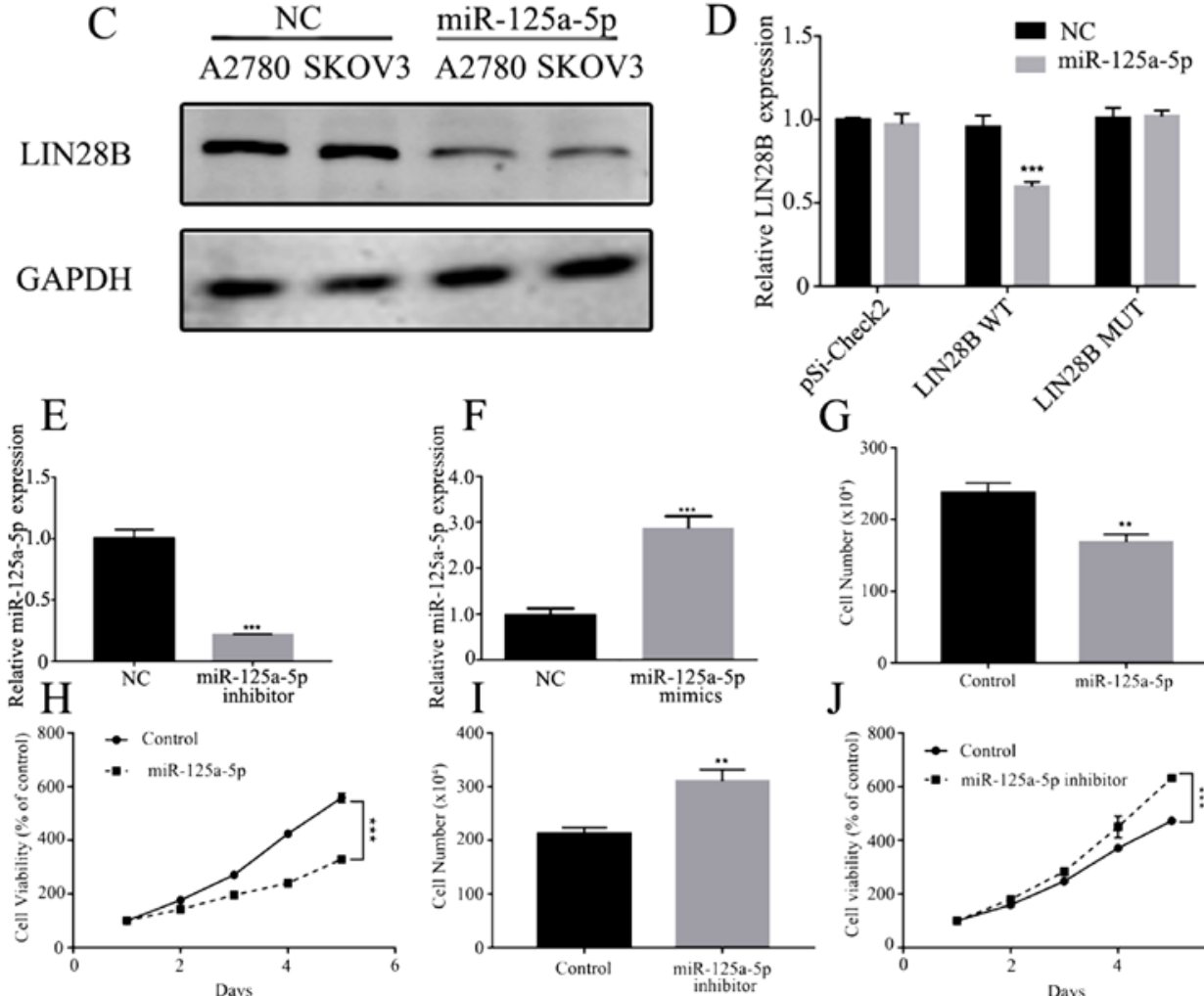
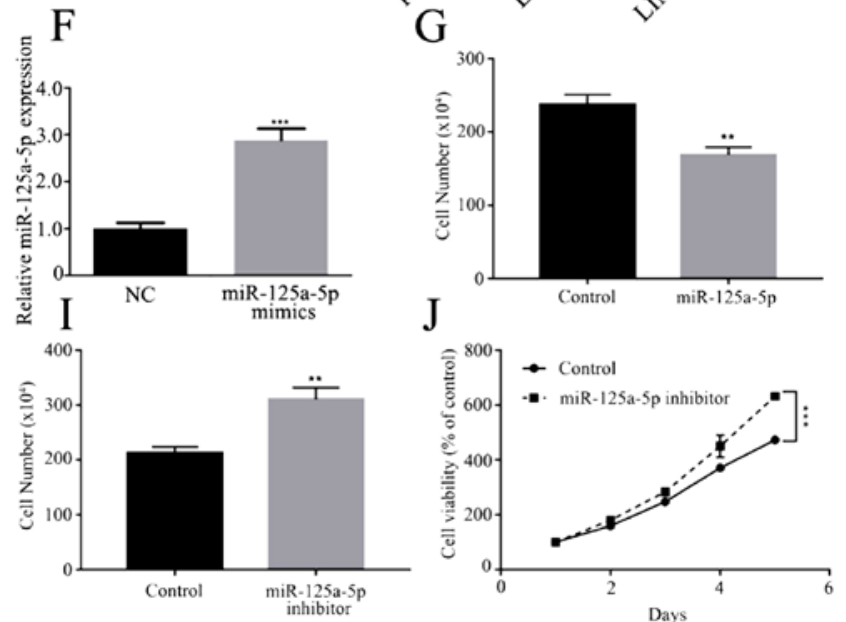

Figure 6. miR-125a-5p directly targets LIN28B and repress proliferation ability in ovarian cancer. (A) Prediction potential targets of miR-125a-5p assessed by TargetScan, miRTarBase, miRDB and TCGA. (B) mRNA expression of LIN28B regulated by miR-125a-5p in A2780 and SKOV3 cells was measured using RT-qPCR. (C) Expression of LIN28B in A2780 and SKOV3 cells transfected with miR-125a-5p were detected by Western blotting. (D) Luciferase reporter activities driven by wild-type or MUT LIN28B 3' untranslated regions were examined in A2780 cells transfected with miR-125a-5p mimics or NC. (E) Expression of miR-125a-5p in A2780 cells transfected with miR-125a-5p inhibitor was evaluated by RT-qPCR. (F) miR-125a-5p expression in A2780 cells transfected with miR-125a-5p mimics was measured by RT-qPCR. (G) Proliferation of A2780 cells transfected with miR-125a-5p was assessed by cell counts assay. (H) Viability of A2780 cells transfected with miR-125a-5p was tested by MTT assay. (I) Proliferation ability of A2780 cells transfected with miR-125a-5p inhibitor was determined by cell counts assay. (J) Viability of A2780 cells transfected with miR-125a-5p inhibitor was tested by MTT assay. Data are presented as the mean $\pm \mathrm{SD} .{ }^{* *} \mathrm{P}<0.01,{ }^{* * *} \mathrm{P}<0.001$ vs. control. miR, microRNA; MUT, mutant; RT-qPCR, reverse transcription-quantitative PCR; NC, negative control; LIN28B, lin-28 homolog B; TCGA, TCGA, The Cancer Genome Atlas. 

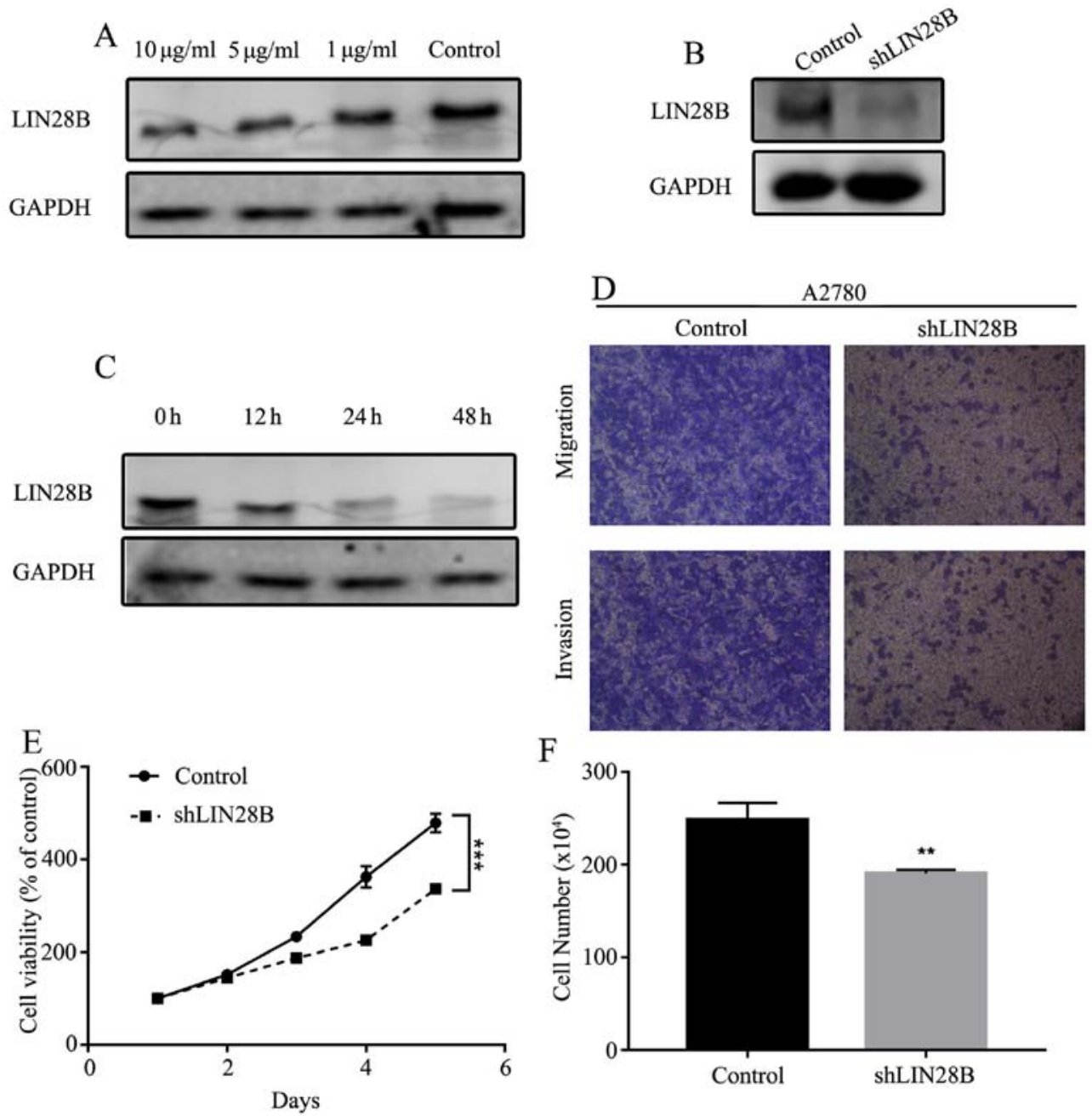

Figure 7. LIN28B expression is inhibited by propofol. (A) Expression of LIN28B in A2780 cells administered with different concentration of propofol was measured using Western blotting. (B) Expression of LIN28B in LIN28B knockdown A2780 cells was assessed by Western blotting. (C) Expression of LIN28B in A2780 cells administered with $10 \mu \mathrm{g} / \mathrm{ml}$ propofol at different times was evaluated using Western blotting. (D) Transwell migration and invasion assay of A2780 cells and LIN28B knockdown A2780 cells. Original magnification, x400. (E) Viability of A2780 cells and A2780 knockdown cells was measured using MTT assay. (F) Proliferation of A2780 cells and A2780 knockdown cells determined by cell counts assay. Data are presented as the mean \pm SD. ${ }^{* *} \mathrm{P}<0.01$, ${ }^{* * *} \mathrm{P}<0.001$ vs. control. miR, microRNA; LIN28B, lin-28 homolog B; sh, short hairpin RNA.

Ovarian cancer is one of the most fatal gynecologic tumor types (26). Currently, therapeutic methods involve multiple approaches that include debulking surgery, chemotherapy and radiotherapy in ovarian cancer, but the curative treatment is surgical resection (27). Anesthesia agents must be used during the surgical processes. However, the role that anesthetics serve in the development of cancer is not fully understood. Propofol, a commonly used intravenous sedative-hypnotic agent administered to induce and maintain anesthesia, has been used since the late 1980s (5). Propofol not only has an anesthetic effect but has also been reported to possess antioxidant, neuroprotective, immunomodulatory, analgesic, antiemetic and anticancer effects $(6,28,29)$. Previous studies have also reported that propofol can suppress tumor growth $(25,30,31)$. Another study revealed that propofol increased the expression of caspase-3 in A549 cells and LoVo cells to induce cell apoptosis (32). Du et al (8) also showed that propofol inhibited cell proliferation, migration and invasion, and induced apoptosis by regulating Sox 4 in endometrial cancer cells. Moreover, Peng and Zhang (33) reported that propofol possessed anti-proliferative and pro-apoptotic properties in gastric cancer via the upregulation of miR-451.
Propofol also has an inhibitory role in A549 lung cancer cells by downregulating miR-372 and inactivating the mTOR and Wnt/ $\beta$-catenin pathways (34). Propofol inhibits proliferation, migration and invasion, and induces apoptosis in gastric cancer cells by upregulating miR-195 and miR-451 $(33,35)$. Cellular proliferation can also be inhibited by propofol via its regulation of several miRNAs, including miR-372, miR-1284 and miR-486, in lung cancer cells $(7,36)$. Overall, propofol inhibits cell viability functions in numerous cancer types. Huang et al (37) revealed that propofol upregulated miR-9 expression and led to the inhibition of cell proliferation and invasion in ovarian cancer ES-2 cells. Moreover, Sun et al (31) found that propofol could decrease miR-374a expression to increase the expression of forkhead box O1, resulting in inhibition of cisplatin resistance and proliferation. The present study evaluated the effects of different concentrations of propofol on two ovarian cell lines. It was identified that propofol had inhibitory effects on cell viability, migration and invasion in a dose- and time-dependent manner. Moreover, the present results are consistent with the aforementioned previous studies, suggesting that propofol can suppress tumors. 
miRNAs, which are non-coding RNAs consisting of 18-25 nucleotides, act as oncogenes or tumor suppressors and can be used as potential biological markers to diagnose, predict and treat different cancer types (38). Previous studies have reported that several miRNAs are regulated by propofol $(25,31)$. The present study analyzed mRNA sequencing data from 453 patients with ovarian cancer in TCGA. For biological processes, these 5,188 genes regulated by miR-125a-5p were mainly enriched in 'biological regulation', including 'cell proliferation', 'growth', 'metabolic process' and 'cell communication', indicating that miR-125a-5p could act as an anticarcinogen to inhibit ovarian cancer by mediating biological regulation. The expression of miR-125a-5p was measured under several concentrations of propofol, and the results indicated that the expression of miR-125a-5p was enhanced in a dose- and time-dependent manner. Furthermore, the positive effect of propofol on miR-125a-5p transcriptional activity was further identified by a luciferase assay. Wu and Belasco (39) revealed the human LIN28 mRNA as a regulatory target of human miR-125b and its homologue miR-125a during neuronal differentiation of embryonal carcinoma cells. Moreover, Zhang et al (11) showed that miR-125a-5p directly targeted LIN28B and suppressed melanoma growth. In patients with colon cancer, it has been revealed that propofol anesthesia is associated with improved survival during colon cancer surgery (40). However, another study suggested that the prognosis and survival of patients treated with propofol and desflurane were not significantly different after breast cancer surgery (30). However, these conflicting results could be attributed to the different types of cancer or to different effects of propofol in vitro and in vivo. The present results demonstrated a significant decrease in LIN28B expression with propofol in a dose- and time-dependent manner. Further investigations revealed that LIN28B KD significantly inhibited cell proliferation and viability. LIN28B was also identified as a direct target of miR-125a-5p, and propofol treatment reduced LIN28B expression. Thus, the results indicated that LIN28B KD led to significantly decreased cell proliferation and viability in ovarian cancer.

In conclusion, the results demonstrated that propofol plays an important role in inhibiting the proliferation, migration and invasion of ovarian cancer cells. Propofol also upregulates the expression of miR-125a-5p to inhibit LIN28B. Therefore, propofol in the surgical treatment of ovarian cancer may be a potential target for improving cancer prognosis and survival $(24,31,41)$.

\section{Acknowledgements}

Not applicable.

\section{Funding}

No funding was received.

\section{Availability of data and materials}

The datasets used and/or analyzed during the current study are available from the corresponding author on reasonable request.

\section{Authors' contributions}

Conception and design: JZe, JZo and YKL. Acquisition and assembly of data: WJT, XZ, FFQ, CYC and TZ. Data analysis and interpretation: CYC, FFQ and XZ. Manuscript writing: JZe, WJT, YKL and FFQ. Paper revision: JZo and WJT. All authors read and approved the final manuscript.

\section{Ethics approval and consent to participate}

Not applicable.

\section{Patient consent for publication}

Not applicable.

\section{Competing interests}

The authors declare that they have no competing interests.

\section{References}

1. Bray F, Ferlay J, Soerjomataram I, Siegel RL, Torre LA and Jemal A: Global cancer statistics 2018: GLOBOCAN estimates of incidence and mortality worldwide for 36 cancers in 185 countries. CA Cancer J Clin 68: 394-424, 2018.

2. Siegel R, Naishadham D, Jemal A and Ahmedin J: Cancer statistics, 2013. CA Cancer J Clin 63: 11-30, 2013.

3. Arnold M, Rutherford MJ, Bardot A, Ferlay J, Andersson TM, Myklebust TÅ, Tervonen H, Thursfield V, Ransom D, Shack L, et al: Progress in cancer survival, mortality, and incidence in seven high-income countries 1995-2014 (ICBP SURVMARK-2): A population-based study. Lancet Oncol 20: 1493-1505, 2019.

4. Coleman RL, Fleming GF, Brady MF, Swisher EM, Steffensen KD, Friedlander M, Okamoto A, Moore KN, Efrat Ben-Baruch N, Werner TL, et al: Veliparib with First-Line Chemotherapy and as Maintenance Therapy in Ovarian Cancer. N Engl J Med 381: 2403-2415, 2019

5. Hsing CH, Lin MC, Choi PC, Huang WC, Kai JI, Tsai CC, Cheng YL, Hsieh CY, Wang CY, Chang YP, et al: Anesthetic propofol reduces endotoxic inflammation by inhibiting reactive oxygen species-regulated Akt/IKK $\beta / \mathrm{NF}-\mathrm{\kappa B}$ signaling. PLoS One 6: e17598, 2011.

6. Vasileiou I, Xanthos T, Koudouna E, Perrea D, Klonaris C, Katsargyris A and Papadimitriou L: Propofol: A review of its non-anaesthetic effects. Eur J Pharmacol 605: 1-8, 2009.

7. Liu WZ and Liu N: Propofol inhibits lung cancer A549 cells growth and epithelial-mesenchymal transition process by up-regulation of microRNA-1284. Oncol Res 27: 1-8, 2018.

8. Du Q, Liu J, Zhang X, Zhang X, Zhu H, Wei M and Wang S: Propofol inhibits proliferation, migration, and invasion but promotes apoptosis by regulation of Sox4 in endometrial cancer cells. Braz J Med Biol Res 51: e6803, 2018.

9. Wang LB, Feng L, He J, Liu B and Sun JG: MiR-125a-5p inhibits the proliferation and invasion of breast cancer cells and induces apoptosis by targeting GAB2. Math Biosci Eng 16: 6923-6933, 2019.

10. Cao Y, Shen T, Zhang C, Zhang QH and Zhang ZQ: MiR-125a-5p inhibits EMT of ovarian cancer cells by regulating TAZ/EGFR signaling pathway. Eur Rev Med Pharmacol Sci 23: 8249-8256, 2019.

11. Zhang Z, Zhang S, Ma P, Jing Y, Peng H, Gao WQ and Zhuang G: Lin $28 \mathrm{~B}$ promotes melanoma growth by mediating a microRNA regulatory circuit. Carcinogenesis 36: 937-945, 2015.

12. Yong W, Yu D, Jun Z, Yachen D, Weiwei W, Midie X, Xingzhu J and Xiaohua W: Long noncoding RNA NEAT1, regulated by LIN28B, promotes cell proliferation and migration through sponging miR-506 in high-grade serous ovarian cancer. Cell Death Dis 9: 861, 2018.

13. Zhou J, Ng SB and Chng WJ: LIN28/LIN28B: An emerging oncogenic driver in cancer stem cells. Int J Biochem Cell Biol 45: 973-978, 2013. 
14. Huang J, Cao D, Sha J, Zhu X and Han S: DLL3 is regulated by LIN28B and miR-518d-5p and regulates cell proliferation, migration and chemotherapy response in advanced small cell lung cancer. Biochem Biophys Res Commun 514: 853-860, 2019.

15. Wang C, Gu Y, Zhang E, Zhang E, Zhang K, Na Qin N, Dai J, Zhu M, Liu J, Xie K, et al: A cancer-testis non-coding RNA LIN28B-AS1 activates driver gene LIN28B by interacting with IGF2BP1 in lung adenocarcinoma. Oncogene 38: 1611-1624, 2019.

16. Dong S, Wang R and Wang H, Ding Q, Zhou X, Wang J, Zhang K, Long Y, Lu S, Hong T, et al: HOXD-AS1 promotes the epithelial to mesenchymal transition of ovarian cancer cells by regulating miR-186-5p and PIK3R3. J Exp Clin Cancer Res 38: 110, 2019.

17. R Core Team: R: A language and environment for statistical computing. R Foundation for Statistical Computing, Vienna, 2014. https://www.R-project.org/.

18. Vasaikar SV, Straub P, Wang J and Zhang B: LinkedOmics: Analyzing multi-omics data within and across 32 cancer types Nucleic Acids Res 46: D956-D963, 2018.

19. Agarwal V, Bell GW, Jin-Wu Nam JW and Bartel DP: Predicting effective microRNA target sites in mammalian mRNAs. Elife 4 e05005, 2015.

20. Chou CH, Shrestha S, Yang CD, Chang NW, Lin YL, Liao KW, Huang WC, Sun TH, Tu SJ, Lee WH, et al: miRTarBase update 2018: A resource for experimentally validated microRNA-target interactions. Nucleic Acids Res 46: D296-D302, 2018

21. Chen Y and Wang X: miRDB: An online database for prediction of functional microRNA targets. Nucleic Acids Res 48: D127-D131, 2020.

22. Livak KJ and Schmittgen TD: Analysis of relative gene expression data using real-time quantitative PCR and the 2(-Delta Delta C(T)) method. Methods 25: 402-408, 2001.

23. Zou J, Li H, Huang Q, Liu X, Qi X, Wang Y, Lu L and Liu Z: Dopamine-induced SULT1A3/4 promotesEMT and cancer stemness in hepatocellular carcinoma. Tumour Biol 39: 1010428317719272, 2017.

24. Zhang J, Zhang D, Wu GQ, Feng ZY and Zhu SM: Propofol inhibits the adhesion of hepatocellular carcinoma cells by upregulating microRNA-199a and downregulating MMP-9 expression. Hepatobiliary Pancreat Dis Int 12: 305-309, 2013.

25. Ye Z, Jingzhong L, Yangbo L, Lei C and Jiandong Y: Propofol inhibits proliferation and invasion of osteosarcoma cells by regulation of microRNA-143 expression. Oncol Res 21: 201-207, 2013

26. Wijnen JA and Rosenshein NB: Surgery in ovarian cancer. Arch Surg 115: 863-868, 1980

27. Park TW and Kuhn WC: Neoadjuvant chemotherapy in ovarian cancer. Expert Rev Anticancer Ther 4: 639-647, 2004.

28. Zhang Z, Zang M, Wang S and Wang C: Effects of propofol on human cholangiocarcinoma and the associated mechanisms. Exp Ther Med 17: 472-478, 2019.
29. Wang J, Cheng CS, Lu Y, Ding X, Zhu M, Miao C and Chen J: Novel findings of anti-cancer property of propofol. Anticancer Agents Med Chem 18: 156-165, 2018.

30. Huang YH, Lee MS, Lou YS, Lai HC, Yu JC, Lu CH, Wong CS and Wu ZF: Propofol-based total intravenous anesthesia did not improve survival compared to desflurane anesthesia in breast cancer surgery. PLoS One 14: e0224728, 2019.

31. Sun Y, Peng YB, Ye LL, Ma LX, Zou MY and Cheng ZG: Propofol inhibits proliferation and cisplatin resistance in ovarian cancer cells through regulating the microRNA 374a/forkhead box O1 signaling axis. Mol Med Rep 21: 1471-1480, 2020.

32. Song J, Shen Y, Zhang J and Lian Q: Mini profile of potential anticancer properties of propofol. PLoS One 9: e114440, 2014.

33. Peng Z and Zhang Y: Propofol inhibits proliferation and accelerates apoptosis of human gastric cancer cells by regulation of microRNA-451 and MMP-2 expression. Genet Mol Res 15: 15, 2016.

34. Sun $\mathrm{H}$ and Gao D: Propofol suppresses growth, migration and invasion of A549 cells by down-regulation of miR-372. BMC Cancer 18: 1252, 2018.

35. Zhang W, Wang Y, Zhu Z, Zheng Y and Song B: Propofol inhibits proliferation, migration and invasion of gastric cancer cells by up-regulating microRNA-195. Int J Biol Macromol 120: 975-984, 2018

36. Yang N, Liang Y, Yang P, Yang T and Jiang L: Propofol inhibits lung cancer cell viability and induces cell apoptosis by upregulating microRNA-486 expression. Braz J Med Biol Res 50: e5794, 2017.

37. Huang X, Teng Y, Yang $\mathrm{H}$ and Ma J: Propofol inhibits invasion and growth of ovarian cancer cells via regulating miR-9/NF- $\mathrm{B}$ signal. Braz J Med Biol Res 49: e5717, 2016.

38. McManus MT: MicroRNAs and cancer. Semin Cancer Biol 13: $253-258,2003$

39. Wu L and Belasco JG: Micro-RNA regulation of the mammalian lin-28 gene during neuronal differentiation of embryonal carcinoma cells. Mol Cell Biol 25: 9198-9208, 2005.

40. Wu ZF, Lee MS, Wong CS, Lu CH, Huang YS, Lin KT, Lou YS, Lin C, Chang YC and Lai HC: Propofol-based total intravenous anesthesia is associated with better survival than desflurane anesthesia in colon cancer surgery. Anesthesiology 129: 932-941, 2018.

41. Ikeda T, Kurasako N, Nishitani K, Okada S and Arai T: Anesthetic management for removal of a giant ovarian tumor using FloTrac X Vigileo monitoring system. Masui 63: 439-442, 2014 (In Japanese).

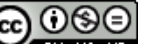

This work is licensed under a Creative Commons Attribution-NonCommercial-NoDerivatives 4.0 International (CC BY-NC-ND 4.0) License. 